the profession or anyone else. At least let had a persistent E.E.G. abnormality in shontall be clear that no victors will emerge from the present dispute and the losens now are the patients. All the previous disputes have been settled so, but I do not recall any of them in which doctors have deliberately delayed the treatment of patients. Surely those who represent the profession and those who represent the Government should be using every effort to end this situation and not exchanging taunts in public. This is not a time for anyone to stand on points of principle which they would be hard put to justify to the general public. The best public comment of the past three months appeared in a letter to the Guardian on 4 Manch from "G.P.'s Wife" from Sussex. I have been stimulated to write this letter by her comment, with which I wholly agree, on the harm now being done to the standing of our profession.-I am, etc.,

Cambridge

GEORGE GODBER

1 British Medical fournal, 1942, 1, 744

2 A National Health Service, Cmnd. 6502. London, H.M.S.O., 1944

3 A Review of the Medical Services in Great Britain. Social Assay, 1962.

4 A Hospital Plan for England and Wales, Cmnd

5 British Medical fournal Supplement, 1955, 1, 220

\section{Long Survival from Acute Leukaemia in} Childhood

SIR,-Everyone would agree with the point made by Drs. Patricia Morris Jones and F. N. Bamford (1 March, p. 510) that we should all be concerned with the quality of life in surviving children who have undergone intensive therapy for malignant disease. However, we regret their misleading implication that the possible long-term central nervous system sequelae in children surviving after treatment for acute lymphoblastic leukaemia (A.L.L.) might be comparable to the gross long-term mental and physical disabilities they have noted in a series of survivors from intracranial neoplasms. Children with C.N.S. tumours sustain damage due to the tumour itself, often of a gross and irreversible nature and possibly compounded by the effects of neurosurgery in many cases, followed up by high-dose radiotherapy approaching the limits of brain tolerance. Children receiving C.N.S. prophylaxis for A.L.L. in remission have no prior overt neurological abnormality, and in suah cases we can more confidently attribute any C.N.S. sequelae to the effects of treatment.

Surely those specialist dinicians particularly involved in the treatment of leukaemic children are already well aware of the potential risk of treatment sequelae, and of their responsibility to conduct appropriate prospective studies? Attention has already been drawn to a previously unrecognized postinradiation syndrome in these children. Nearly half of a group of children in the M.R.C. trial employing C.N.S. prophylaxis developed pronounced symptoms of somnolence, lethargy, and anorexia 5-6 weeks after completing irradiation, ${ }^{1}$ but it must be emphasized that this was of short duration and lefit no sequelae. We too have found eleotroencephalographic changes in about half of 30 children having sequential E.E.G.s during and following C.N.S irradiation. But few of these children have term follow-up. Some information on the long-term effects of C.N.S. prophylaxis is already available. Verzosa et al. ${ }^{2}$ studied 100 ohildren surviving 2-10 years after such treatment and reported no abnormal effects on intelligence, cy.tology, or growth characteristics with the exception that those children who had had spinal irradiation did show some stunting of growth.

Inappropriate or undue concern for the future quality of life in children with malignant disease should not be allowed to discourage us from applying the treatments currently available that are known to offer our patients the best chance of survival.-We are, etc.,

JOHN FREEMAN

J. S. Malpas

Department of Medical Oncology and Radiotherapy, St. Bartholomew's Hospital, 1 Freeman, J. E., Johnston, P. G. B., and Voke,
J. M., British Medical fournal, 1973, 4, 523 .
2 Verzosa, M., et al., Proceedings of the American Association for Cancer Research, 1974, 15, 98.

SIR,-Drs. Patricia H. Morris Jones and F. N. Bamford (1 March, p. 510) raise some pertinent points. Those oncologists who have been involved in treating ahildren with malignant disease have always had in the forefront of their minds the long-term effects of their therapy. But it is not with faint heart that long survival and even cure have been achieved in the treatment of nephroblastoma, acute lymphoblastic leukaemia, or sarcomas. Concerted and somewhat "over-aggressive" therapy was needed. disease then it was apparent that a cure was possible. Then carefully controlled diminution in the various suocessful regimens employed could be considered. A good example is the no' widely acknowledged fact that prophylactic craniospinal irradiation in acute lymphoblastic leukaemia could be successfully replaced with cranial irradiation and intrathecal methotrexate, thus sparing vertebral bone marrow reserves and possibly preserving growth.

The authors are making an important point of the Florence Nightingale principle of "do your patient no harm" but perhaps more relevant to their argument is the need for greater expertise in the field of paediatric onoology and a somewhat better-informed and more balanced exposure in the mass media so that the distraught parent will have confidence in those people who treat, or rechild.-I am, etc.,

Chester Beatty Research Institute,
Sutton, Surrey

C. L. GAUCI

\section{Treatment of Myeloma}

SIR,-The recent review of myelomatosis by Dr. J. S. Malpas (30 November, p. 520) focuses attention on the therapeutic dilemma currently facing physicians. The natural history of this disease and the relatively modest response that has been reported to date with most of the therapeutic regimens now in use is, no doubt, the basis for the continued use of less aggressive treatment schedules and a willingness to settle for good palliative therapy. On the other hand these same observations should, perhaps, When children stopped dying from the frain from treating, the fatal disease in their stimulate an evaluation of alternative approaches to management in which eradication of the malignant clone receives greater attention.

Thus though the advantages of combination cytotoxic chemotherapy sahedules over the use of single drugs have not yet been clearly defined, at least three observations raise questions about the continued use of programmes available at present. Firstly, while median survival has been improved, most patients still die with residual disease and significantly impaired haematological reserve. Secondly, it seems probable that the use of cycle-non-specific drugs such as phenylalanine mustard contributes significantly to the situation by progressive depletion of the progenitor cells in the bone marrow. Thirdly, it is now alear that cytotoxic chemotherapy is capable of reducing tumour mass and that this is associated with the recruitment of an inoreasing number of malignant cells into cycle. This latter situation may be identified by a rise in the labelling index and tumours with this kinetic pattern should, logically, be much more vulnerable to cycle-specific agents.

In recognition of these arguments we are prospectively evaluating a programme in which two distinct therapeutic phases may be reoognized. Initially a combination of vincristine, procarbazine, melphalan, and prednisone is employed since our experience with 71 cases studied in the past 24 months has demonstrated this to be highly effective in gaining rapid control over bone pain, tumour mass, and reversible renal complications. It is particularly noteworthy that these four drugs used simultaneously in a oneweek course with a five-week rest period have a high degree of patient acceptability. This induction combination is repeated two or three times, and when the labelling index has risen significantly cycle-specific drugs are employed in an attempt to eradicate the disease without irreversibly damaging the haemopoietic reserve.

Quite clearly such an approach implies the availability of intensive haematological support, relatively large numbers of patients, and sophisticated laboratory facilities. We would be interested to hear of other investigators pursuing similar lines of clinical study.-We are, etc.,

Peter Jacobs

DANNY DUBOVSKY

Leukaemia Service,

Haematology,

University of Cape Town,

Cape Town

\section{Pseudopatients}

SIR,-The careful distinction that was made in your leading anticle (28 December, p. 729) between pseudopatients and simulated patients is appreciated. Simulated patients are carefully trained by health professionals to simulate accurately an actual patient with high fidelity for purposes of teaching and evaluation. They should not be confused with pseudopatients, who are untrained patient imposters who gain entrance into a health care system for purpose of evaluation. Your article became confused about health care evaluation in relation to simulated patients and what was described as my naive suggestion that they should be used to evaluate health care delivery. Several aspects concerning the correct use of simulated 
patients in such evaluations were overlooked. Evaluation should not be considered as anything but constructive for those evaluated. It should provide feedback to improve patient care. Those involved in an evaluation with simulated patients should agree to the valuation. In addition, they must be instrumental in the design of the evaluation, especially the observations to be made by the simulator. Of course, the simulated patient does not have to be personally involved in the evaluation.

Since the simulated patient offers a standardized, unvarying medical problem, subsequent analysis of health needs produced by those who cared for the simulated patient can be carried out. However, if the simulated patient is to be involved in observation it is imperative that he be trained for consistency and objectivity. The anonymity of the simulation assures that no special treatment is given to this patient either consciously or unconsciously, as he is no reoognized as being different from the real patients in the system. The statement that simulated patients would be a drain on health care costs seems exaggerated. The cost of the odd non-patient should be well overbalanced by the value of the exercise in improved efficiency and effectiveness in real patient care. Quality control, to be effective, has a calculated cost. Though your article mentions other methods for evaluating health care, none is as direct as measuring the effect of health care delivery on patients by putting a standardized patien into the system. Many factors important to patient care cannot be detected by visits or by interviews of patients who are dependent on the health care system in which they are involved.

The great value of feedback provided by simulated patients to students, physicians, and nurses over the 12 years that I have utilized the technique has been amply demonstrated. In addition, the persons evaluated almost always appreciate the value of the information and insist on more evaluations of themselves by this technique. -I am, etc.,

H. S. BARROWS

McMaster University,

Hamilton, Ontario

\section{Drug Combinations for Anaesthesia}

SIR,-Dr. M. W. P. Hudson (9 November p. 345) advocates the use of intravenous methohexitone followed by diazepam (up to $10 \mathrm{mg}$ ) for induction of anaesthesia prior to endotracheal intubation. Since reading his letter I have tried this method in 25 inpatients (20 male, five female) soheduled for oral surgery. After intravenous injection of $80 \mathrm{mg}$ methohexitone and $10 \mathrm{mg}$ diazepam the patients were ventilated vigorously for one minute with nitrous oxide/oxygen and halothane $2 \%$ or, for very robust patients, $3 \%$. Conditions for intubation were considered to be difficult in 14 patients and impossible in four (requiring the use of suxamethonium). As part of a separate study arterial blood samples were taken for blood gas analysis as soon as stable anaesthesia was obtained. Surprisingly, anterial oxygen tensions $\left(\mathrm{PaO}_{2}\right)$ of less than $10.6 \mathrm{kPa}(80 \mathrm{~mm}$ $\mathrm{Hg}$ ) were found in five out of 17 patients, though clinically ventilation seemed to be adequate and the patients were breathing $35-40 \%$ oxygen.
To decide whether this effect was due to the drug combination 10 fit patients aged 30-42 years (nine male, one female) due for minor surgery had anaesthesia induced with 80-100 mg methohexitone and $10 \mathrm{mg}$ diazepam. The jaw was supported once the patient was asleep to avoid respiratory obstruction. Arterial blood samples were taken 2-3 min after induction while the patients were still breathing air and recovering from the transient apnoea which is a feature of this form of induction. Several were light enough to react to the needle prick. Arterial $\mathrm{Po}_{2}$ in these patients varied between $4 \cdot 12$ and $8.65 \mathrm{kPa}$ (31 and $65 \mathrm{~mm} \mathrm{Hg}$ ). The mean value $( \pm$ S.D.) was $6.45 \pm 1.21 \mathrm{kPa}(48.5$ $\pm 9.1 \mathrm{~mm} \mathrm{Hg}$ ). Slight cyanosis was detected in only one of these patients. In a 65-yearold woman having a similar induction $\mathrm{PaO}_{2}$ was $4.79 \mathrm{kPa}$ (36 mm Hg). These figures suggest that transient marked hypoxia is the rule with this drug combination used in patients breathing ambient air and presumably that funther doses of methohexitone or any degree of respiratory obstruction (which may be so difficult to detect $^{1}$ ) will prolong the hypoxic period.

We can expect to read more reports of deaths during dentistry ( 9 November 1974, p. $352 ; 8$ February 1975 , p. 341 ) as long as this drug combination is used without oxygen enrichment, the case for which was so forcibly advocated in your recent leading article (8 February, p. 293). Reading the reports of the inquests on the unfortunate victims, one cannot but help feeling that by the time the patient has collapsed or become cyanosed and the alarm has been raised gross hypoxia has probably been present for a considerable period of time and recovery is unlikely. - I am, etc.,

\section{J. P. ALEXANDER}

Belfast City Hospital,

Belfast

1 Wise, C. C., et al., British Medical fournal, 1969,

Skin Reactions to Beta-blockers

SIR,-Since our original report ( 9 November, p. 321) we have extended our observations to a total of 48 patients with cutaneous reactions to practolol. Thirty-two of these patients have subsequently been treated with alternative beta-blocking agents (26 with oxprenolol, four with propranolol, and two with both). Fourteen of these patients had previously been challenged orally with practolol and all had developed a rash as previously described-usually within 2-3 days. No patient developed skin lesions during periods of up to 30 months' treatment with the alternative beta-blocking agents. In eight patients the practolol-induced rash was still present when alternative treatmen was started and in all of them it cleared completely within a few weeks. We have also observed conversion from positive to negative serology for antinuclear antibody in three patients subsequently treated with oxprenolol.

Despite the report by Dr. B. St. C. Cumberbatch (30 November, p. 528) of a psoriasiform skin reaction associated with oxprenolol treatment our observations demonstrate a lack of cross-reactivity between practolol and other beta-blocking agents with respect to these side effects. On the present evidence the advice of the manufacturers $^{1}$ to treat practolol-sensitive patients with alternative beta-blocking agents appears well founded.-We are, etc.

R. H. FELIX F. A. IVE

M. G. C. DAHI

University Department of Dermatology,

Royal Victoria Infirmary, 1 Downie, C. C. Adverse reactions associated with
practolol (Eraldin and Eramid). Letter to
Medical Practitioners, I.C.I. Ltd., 9 October
1974.

SIR,-It has been reported that practolol may induce acute generalized psoriasiform skin lesions $\mathrm{s}^{\mathrm{l}-3}$ and a recent report of an apparent acute exacerbation of psoriasis occurring in a patient taking oxprenolol suggests that other beta-blockers may share this side effect. As far as we are aware 3 propranolol has not been so incriminated and thus the following case is of interest.

The patient, a 63-year-old woman with mild hypertension and renal impairment, was started on oral propranolol $40 \mathrm{mg}$ twice daily in May 1973. In the previous six years since her hypertension had first been noted by her general practitioner she had received various antihypertensive regimens, none of which had included a beta-blocker. There was no past history of skin disorder. In May 1974 without change in her propranolol dosage, she developed an exfoliative psoriasiform eruption involving the trunk, scalp, limbs, and hands, and necessitating admission to hospital. Treatmen with local coal tar preparations produced marked erythema and subsequently petroleum jelly only was used. Skin biopsy was performed and the histological picture was not that of psoriasis. Sistological picture was not that of psoriasis. Sections showed hyperkeratosis overlying a focally atrophic epidermis with evidence of epidermotropism in places. The dermis showed marked elastosis and free melanin pigment was scattered throughout the papillary dermis. A moderate bu pleomorphic infiltrate was noted in the dermis and was predominantly perivascular in distribution. In general the appearances were considered compatible with a lichenoid drug eruption. As the patient's blood pressure appeared to have settled propranolol was discontinued in June 1974 and has never been restarted. Her skin lesions were slow to clear, but by January 1975 no trace of any abnormality remained. During this period, however there was a severe deterioration in her rena function which has proved to be irreversible.

While it is impossible to be sure that this condition was induced by propranolol, the oocurrence of such lesions in a woman of this age is unusual and the temporal relationship of the psoriasiform eruption to the administration of propranolol was similar to that seen with practolol. ${ }^{2}$ Propranolol is now a commonly used drug and this complication must be rare, though it is conceivable that such cases may be missed in view of the long interval between commencement of the drug and the onset of symptoms.-We are, etc.,

Paul L. Padfield

D. G. BEEVERS

M.R.C. Blood Pressure Unit,

Rebecca Cochran A. MCQUEEN

University Department of Dermatology,

Western Infirmary,

1 Ridley, C. M., British Medical fournal, 1974, 4 229, 719. H., Ive, F. A., and Dahl, M. G. C. British Medical fournal, 1974, 4, 321. M. G. C.,
Department of Health and Social Security, Department of Health and Social Security,
Committee on Safety of Medicines, Adverse Re-

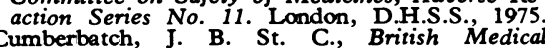
fournal, 1974, 4, 528 . 